\title{
The Methodologists: a Unique Category of Scientific Actors
}

\author{
NiCOLE C. NELSON \\ UNIVERSITY OF WISCONSIN-MADISON
}

\begin{abstract}
This essay introduces a new analytical category of scientific actors: the methodologists. These actors are distinguished by their tendency to continue to probing scientific objects that their peers consider to be settled. The methodologists are a useful category of actors for science and technology studies (STS) scholars to follow because they reveal contingencies and uncertainties in taken-for-granted science. Identifying methodologists is useful for STS analysts seeking a way into science in moments when it is no longer "in the making" or there is little active controversy. Studying methodologists is also useful for scholars seeking to understand the genesis of scientific controversies, particularly controversies about long-established methods, facts, or premises.
\end{abstract}

\section{Keywords}

STS methods; controversy studies; laboratory studies; reproducibility

Science and technology studies (STS) has relatively few analytical terms for distinguishing between types of scientific actors. While it is common for analysts to use the language of disciplines, field theory (Panofsky 2011), or social worlds (Clarke and Star 2008) to delineate the spaces within which scientists act, our vocabularies for describing the different actors at work in these spaces are under-developed. This is especially evident in comparison to the abundance of analytical terms available for describing actors coming out of social and historical studies of technology: consumers (Cowan 1976), system builders (Hughes 1979), lead users (von Hippel 1986), lay end users (Casper and Clarke 1998), non-users (Oudshoorn and Pinch 2003), and so forth. Social worlds theory offers the most richly elaborated vocabulary for describing the actors in a particular arena, offering terms such as "entrepreneurs" to describe those who are deeply committed to a particular social world or "implicated actors" to describe those who are silenced or excluded (Clarke and Star 2008). These terms capture something of actors' positioning at the center or the margins of a space, but they do not capture any features of the work performed by different actors-perhaps deliberately so, since social worlds theory is by design a general approach that aims to help analysts make sense of a wide variety of social situations, not just scientific ones.

In this essay I will introduce a new category of actors at work in scientific spaces: the methodologists. As I will explain in more detail below, these actors are defined by the type of scientific work that they perform in their respective fields: while their colleagues aim to establish

Nicole C. Nelson, Email: nicole.nelson@wisc.edu

Copyright (C) 2020 (Nicole C. Nelson). Licensed under the Creative Commons Attribution Non-commercial No Derivatives (by-nc-nd). Available at estsjournal.org. 
or refine findings, methodologists aim to establish or refine methods. Within a given field this type of actor may be rare or ubiquitous, and their work may be highly valued or associated with lowstatus, marginal positions. Whatever the case, the methodologists are a useful category of actors for STS scholars to follow because their work often entails disrupting the settled science of their colleagues, allowing analysts to see contingencies and uncertainties in scientific processes even in moments where there are few active controversies. Methodologists can also play important roles in controversies or generate stockpiles of knowledge that can be mobilized by other actors in moments of disagreement. I illustrate some of these dynamics using examples from a variety of laboratory ethnographies, histories of experimental work, and my own research.

\section{The Methodologists}

The development and refinement of scientific methods is work that most, if not all, scientists perform. So what distinguishes methodologists from scientists more generally? I propose a definition drawing on the scholarship of Hans-Jörg Rheinberger (1997): methodologists are scientists who treat particular tools, processes, or techniques as "epistemic things," while their colleagues treat them as "technical things." Rheinberger defines epistemic things as the objects of inquiry in a scientific program, and he contrasts them with technical objects that are considered adequately stabilized, well-known, and can be used as tools for manipulating the objects of inquiry. To illustrate the distinction and the relationship between epistemic and technical things, he offers the example of DNA sequencing: in the 1970s sequencing was a "scientific object par excellence," but as these techniques became more stabilized and routine they "transformed into technical objects" to be used in the service of asking other scientific questions. "Today," Rheinberger writes, "every biochemical laboratory can order a sequence kit ... and perform the sequence reaction routinely in a semi-automatic machine" $(1997,30)$.

This account is accurate but incomplete. Many scientists do use sequencing technologies as tools for probing objects of interest, but this does not mean that sequencing technologies are devoid of epistemic interest for all scientists. Even as some researchers are using sequencing machines to characterize the mutations in a patient's cancerous tumor or to study the genetic relationships between different species, other researchers are developing methods to improve the accuracy of base pair calling or to perform sequencing using smaller amounts of genetic material. While in some cases the scientists who continue to probe the contours of sequencing techniques might be sequestered away in private companies or working at some remove from those who are routinely using the techniques, in other cases they may have offices just across the hall from one

\footnotetext{
2 Rheinberger emphasizes that his definition of epistemic and technical things is "functional rather than structural" $(1997,30)$, and that whether something functions as an epistemic or a technical thing depends on how it is configured within an experimental system. Rheinberger does not comment on the dynamics of the situations I investigate here-where an object is treated as both a technical and an epistemic thing within a scientific field-but his functional definition seems to allow for such scenarios. My discussion here should be therefore be taken as an extension of Rheinberger's framework rather than a challenge to it.
} 
another. It is these scientists, who build their careers studying the contours of objects that their colleagues use as tools, that I call the methodologists.

An example from my own research will help to illustrate the argument (Nelson 2013; 2018). In the field of animal behavior genetics, researchers typically draw on a variety of relatively standardized tests for assessing the behavior of their animals. If, for example, a researcher creates a mouse line with a novel transgene and is interested in whether this gene impacts anxiety, she will likely use one or more common behavioral tests for assessing anxiety. ${ }^{3}$ The majority of these tests have been in use in the field for several decades at least, such as the "light-dark box" (first described in 1980 by Jacqueline Crawley and Frederick Goodwin) or the "elevated plus maze" (first described in 1986 by Sharon Pellow and colleagues). These tests fit well with Rheinberger's definition of technical things: They are entities that many animal behavior geneticists consider to be well known and adequately stabilized, and which they use as tools in the service of studying more epistemically interesting objects (in the example above, genes). They are also commercially available, and to some degree automated. Scientific equipment companies sell these mazes as standardized pieces of experimental apparatus and offer computerized video tracking systems to automate data analysis. ${ }^{*}$

And yet, a number of animal behavior geneticists continue to conduct research on the tests themselves, even as their colleagues are using these tests as tools in their research programs. Scientists have proposed modifications to the elevated plus maze design (Fraser et al. 2010), asked whether mazes built of plastic or of metal produce different data (Hagenbuch, Feldon, and Yee 2006), and investigated whether a mouse's activity levels might interfere with the interpretation of common measurements taken in these standardized experiments (Milner and Crabbe 2008). For this small group of animal behavior geneticists, behavioral tests remain epistemically interesting, and they are reluctant to agree with their colleagues that these tests are adequately stabilized or well known enough to be used as mere tools. For some this methodological work was one strand within a diverse scientific portfolio; others centered their careers around behavioral test development and refinement work.

One of the senior scientists that I followed during my fieldwork, Dr. Smith, made clear to me this distinction between his own methodologically focused research agenda and those of his

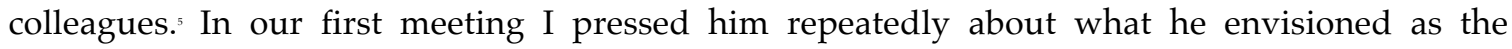
outcomes of his research, expecting to hear more about genetic predispositions to addiction disorders. He replied:

You know, [my collaborator] and I aren't going to find any genes, because we're not looking for them. My [other] collaborators are happily, busily, looking for them. I'm happily, busily, trying to provide them with a test that they can attach to the gene finding effort. ... I see it as kind of a service mode in a sense, that if we can help people use more bulletproof tests, then they're less likely to misinterpret behavioral data as they do

${ }^{3}$ See (Crawley 2007) for an example of a textbook that helps researchers who are new to behavioral testing select appropriate tests from the existing suite of tests.

4 See for example https:// www.panlab.com/en/products/elevated-plus-maze-panlab

5 The names of scientists in the fieldwork examples used in this paper are pseudonyms. 
investigations of gene function. So that, I think, is what we really hope would come out of [our research]—-that science will get better. That there will be better science done.

Dr. Smith is an exemplar of the type of scientific actors that I am calling the methodologists. He directed a research center where many of his colleagues treated the behavioral tests that were the focus of his epistemic interests as adequately stabilized tools. This work on behavioral tests was a core component of his research agenda, and of his identity as a scientist. This is not to say that methodologists engage only in methodological work and not also in work that produces scientific findings of a more expected variety. Dr. Smith published numerous studies throughout his career establishing links between particular mouse strains or genes and behavioral phenotypes, although he did not consider that to be his primary focus at the time that I interviewed him. What distinguished Dr. Smith as a methodologist was his enduring interest in refining existing scientific tools to enable others, in time, to create better scientific facts.

\section{Clarifications and Caveats}

A few clarifications and caveats are in order to clearly delineate the actors and the type of methodological work I want to draw attention to. First, my definition is intended to exclude the ubiquitous maintenance/troubleshooting work that scientists may be highly skilled in but consider epistemically uninteresting. As Kathleen Jordan and Michael Lynch (1992) demonstrated in their ethnographic investigation of "mundane" genetic engineering techniques, even supposedly stabilized tools still require intervention and manipulation, and researchers may develop personalized variations for performing a technique. While in some cases scientists may engage in these activities because of an interest in the technique itself, in most instances this labor is motivated by a more pragmatic desire to simply get a technique to work for particular purposes (or in the hands of a particular researcher). In her study of molecular biology laboratories, Karin Knorr Cetina (1999) noted that a significant amount of time was devoted to "maintain[ing] the laboratory as a well-equipped, well-stocked repository of tools and resources" $(1999,85)$. She argued, however, that the molecular biologists she studied were in general quite uninterested in the inner workings of their experimental systems. They manipulated various parameters until the experimental system was functional again, but they "did not, in the process, do experiments to investigate why the problems arose or to explain the obscure data" $(1999,92)$. Knorr Cetina's molecular biologists were no doubt skillful in maintaining the cell lines, plasmids, buffers, and enzymes that they needed for their research, but for them these were tools for setting up experiments to answer other questions, not epistemically interesting entities in and of themselves. In contrast to this pragmatic attitude towards reagents and experimental systems, methodologists can be distinguished by their enduring interest in the inner workings of these same kinds of elements.

- The emphasis in the original highlights the alignment between Knorr Cetina's description of this work and Rheinberger's definition of technical things. 
Second, the objects that methodologists investigate do not have to be tools or protocols in order to fit my definition; they may be assumptions or premises that are generally taken for granted and enable work within a particular field, or past results that are generally accepted to be true and used as a justification for other research. Researchers who describe themselves as interested in the "foundations" of physics or mathematics might fall under this description, in that they specialize in probing the assumptions that their colleagues make in order to do their work. This clarification is relevant not just for theoretical scientific practices-methodologists' work may still be motivated by an interest in foundational assumptions even in fields where scientific work involves substantial material components. Robert Kirk's (2012a; 2012b) description of James Reyniers' (1908-67) research offers such an example. Reyniers sought to challenge the assumption that the animals used for biomedical research were adequately standardized, which he did not by probing existing tools but by developing an entirely new suite of technologies and practices for producing "germ-free" animals.

A third caveat is that the definition I have offered here will be difficult to apply in situations where the distinction between epistemic and technical things is in flux. This situation is common at the intersections of fields where different orientations towards a shared object come into contact, or at the leading edges of a field, where advancing knowledge production agendas relies on advancing the technical frontier. Nicolas Rasmussen's (2014) account of recombinant DNA research in the 1980s provides an illustration of the problems with attempting to make distinctions between epistemic and technical things in such spaces. Rasmussen argues that techniques for cloning genes and expressing them in bacteria were, in this time period, valuable tools and scientifically interesting systems-cloning the insulin gene was both a way to produce a novel pharmaceutical product and a way to study gene expression in higher organisms. In such situations is it not clear that there is much analytical benefit in attempting to identify a group of methodologists as such. Other STS techniques for studying science in action, such as actornetwork theory, are likely more appropriate for that task and do not come with the risk of "limit[ing] in advance the sort of beings populating the social world" (Latour 2005, 16). As I will explore in more detail below, looking at the activities of methodologists offers more of an advantage when studying seemingly settled science that otherwise lack an obvious analytical entry point.

A final note is that the concept I am putting forward here is intended to be taken primarily as a category of actors rather than a kind of work, even while there is substantial slippage between the two. A comparison to the concept of the "core-set" - one of the few analytical STS concepts available for distinguishing between types of scientific actors-will help to illustrate why I choose this emphasis. Harry Collins (1981) described core-sets of scientists as entities that arise in response to specific experimental controversies and disperse once the controversy is settled. He argued that the members of a core-set typically enter a dispute, make a contribution (eg. pointing out a flaw with an experimental setup), and then leave it quickly, and that "the general pattern is for scientists either never to become involved in a core-set at all, or to be involved for a brief period only" $(1981,13)$. In contrast, methodologists' engagement with these issues is typically enduring rather than transient. While methodologists might participate in 
a core-set during moments of controversy, their interest in probing established tools and assumptions is not necessarily responsive to or bounded by specific experimental controversies. Many of the methodologists I have interacted with attributed their sustained interest in methodological issues to their self-identity as scientists (eg. Dr. Smith's assertion that questioning supposedly settled tools and techniques is an important part of what it means to do good science or be a good scientist) or as a part of their personality (one methodologist I interviewed described himself as someone who "quite likes a good fight" and attributed his methodological work to that aspect of his character). While it is not necessarily the case that all scientists who question supposedly stable tools or premises exhibit a lifelong interest in this type of work, identifying those individuals who do have an enduring interest in methodological work is analytically useful for STS scholars. Since the methodologists' work is not tied to a specific moment of controversy, following these actors offers scholars a way into otherwise settled science.

\section{Mapping Methodological Orientations onto Scientific Fields}

One slippery aspect of the definition of the methodologists that I have offered-that they are actors who treat their colleagues' technical things as entities with epistemic interest-is defining who exactly counts as a colleague. This is important for two reasons. First, it is quite common for scientists coming from different backgrounds to have different orientations towards an objectone field's research object often is another field's tool. Without this provision the definition might expand so much that almost any scientist could be said to be a methodologist-just as an overly flexible interpretation of the term "boundary object" has led to concerns that anything can count as a boundary object (Star 2010). Second, the impact of methodologists' work is likely to be quite different when they belong to the field whose methods or premises they are studying. Outsiders are more easily dismissed than actors that are considered members of the community in question. It is useful, therefore, to hold on to the notion of a scientific field (or discipline, or arena) even though the boundaries of a field are difficult to delineate analytically, especially in interdisciplinary spaces (Panofsky 2011).

In animal behavior genetics, methodologists constituted a small but respected subset of their field. The majority of practitioners were interested in links between behaviors and particular genes, neurotransmitters, and brain regions; but those who were engaged in refining behavioral models (such as Dr. Smith) still held leadership positions on editorial boards or in professional societies, were recognized with awards by these societies, were well supported with funding, and regularly collaborated with other animal behavior geneticists whose primary interest was in establishing genetic facts. This configuration, however, is only one of many possible ways that methodological orientations might intersect with scientific fields. In other instances, methodologists might be almost entirely absent from a field, or they might be abundant. The valuation of methodological work in a field can likewise vary, from being a high-status activity to being regarded as mere service work. The specific configuration of these parameters will generate different constraints and opportunities for methodologists in their respective fields. 
Knorr Cetina's (1999) description of research in high-energy physics offers an example of a field where methodologists seem abundant. Whereas the molecular biologists she studied seemed largely uninterested in the reasons why their experimental systems malfunctioned, she described her high-energy physicists as intensively concerned with understanding the components and processes that made up their experimental systems. From the moment the first components to build a new detector arrived, they engaged in a process of attempting to understand the detector's behavior-how it responded in different scenarios, how the detector's aging would affect those responses, scenarios in which short-term instabilities might arise, and so on. Knorr Cetina emphasized that these investigations were not simply motivated by pragmatism. She pointed to a set of experiments examining how nitrogen gas became trapped in different parts of the detector as an example of this orientation, since the experiment was not needed to perform or interpret future experiments (the group had already decided not to use nitrogen again in future work) $(1999,59)$. Knorr Cetina described this "reflexive epistemics" $(1999,46)$ as permeating the world of high-energy physics. She went so far as to argue that these physicists "substitute[d] a concern with their own internal production circuitry for a concern with real-time objects found in other sciences such as molecular biology" $(1999,56)$. This is not to say that Knorr Cetina's high-energy physicists did not also use detectors as tools for asking other scientific questions, but it is clear from her description that the detector's behavior remained surprising and epistemically interesting for many practitioners even as it was being employed in the service of investigating other phenomena. Further research might help to determine whether this interest in experimental systems prevailed in the field of high-energy physics at large, or whether Knorr Cetina just happened to fall in with a group of methodologists.

If high-energy experimental physics offers an example of a scientific field dominated by methodologists, genome science offers an example where methodologists are at the edges-or even outside- of the field. In their study of bioinformaticians, Jamie Lewis and Andrew Bartlett (2013) explored the unclear status of computational work in post-genomic science. They argued that bioinformaticians' epistemic interest in processes such as the transformation of raw fluorescence intensity measurements into meaningful microarray data were not shared by the biologists they worked with, who saw these processes as necessary steps to asking other questions. The low status of this work within the field left bioinformaticians "position[ed] at the institutional edges of the academy" (2013, 260). Relegated to a marginal position, the bioinformaticians Lewis and Bartlett interviewed alternated between asserting that bioinformatics offered a valuable service to biologists and asserting that bioinformatics should be viewed as a discipline or a research specialty in its own right.

The example of bioinformatics pushes the definition of methodologists I have offered to its limits, since it is no longer clear that bioinformaticians and biologists belong to the same scientific field. Some configurations of methodologists within fields might be more difficult to maintain than others, and Lewis and Bartlett's case study suggests that situations where methodologists are in the minority and their work is considered low status might be especially precarious. In such situations the active creation of separate niches within the field-or even the creation of a new field itself-might emerge as a technique for resolving the tension of being 
relegated to a marginal position. Caitlin Wylie's (2015) study of preparators in paleontology offers another example of how actors performing seemingly low-status technical work resist this framing and work actively to create niches in which they can operate autonomously within their institutions.

\section{The Value of Attending to Methodologists}

Wherever they may be positioned in scientific fields, the methodologists are a useful group of actors for STS scholars to attend to because they open up processes of scientific knowledge production for examination. As Bruno Latour (1987) has famously argued, one of the difficulties of studying technoscience is that the uncertainty and contingency of scientific practice is "black boxed" as facts and technologies settle. Latour's remedy for this problem is to study science in the making, a method which entails following scientific actors as they are attempting to form black boxes. As Latour and others have pointed out, controversies are especially rich for STS study because scientific actors themselves do much of the work of revealing underdetermination and alternative interpretations in these moments.?

Following methodologists is another technique for capitalizing on work done by scientific actors to open up scientific instruments and processes for examination. As I have explained already, methodologists are typically working in situations that are not controversies in the classic sense; rather, they are tinkering in established black boxes and preventing these boxes from becoming completely opaque. Seeking out methodologists as a site of study can therefore provide STS scholars an alternative way into arenas where there are few controversies concerning the subject of interest.

My study of the elevated plus maze illustrates these dynamics (Nelson 2013; 2018). As the maze became more widely and commonly used, it also came to be seen by many as simply a "test of anxiety" - an unremarkable, uncontroversial entity in the landscape of science. Methodologists in animal behavior genetics have pushed back on this framing over the years, drawing attention to the caveats that needed to be ignored for this framing to hold. For example, they pointed out that the test had been validated by using particular classes of anti-anxiety drugs in the 1980s, but newer anti-anxiety drugs that came onto the market in the 1990s did not change mouse behavior in the same way (Kurt, Arik, and Celik 2000; Moser 1989; Silva, Alves, and Santarem 1999). By continuing to conduct studies on the maze itself and to publish and cite this research, methodologists allow analysts a glimpse of the complicating information that is erased (such as the incongruent findings from different classes of anti-anxiety drugs) in order to naturalize tools and the findings produced with them. Seeking out the publications of methodologists or interviewing methodologists therefore offers analysts an additional way into studying seemingly black-boxed entities, supplementing existing methods of studying controversies or science in action.

- See Chandra Mukerji (2007) for an overview of the controversy case study approach in STS. 
Attending to methodologists is valuable not just as an alternative approach for cases where controversies are not abundant; the category can also enhance our understanding of how scientific controversies flare and fade. The type of work that methodologists engage in typically contains the grains of a controversy, because it reveals problems with methods, findings, or assumptions that others want to treat as taken for granted. Even improvements in methods can pose this problem by calling into question findings generated with older methods." Some methodologists deploy their findings in deliberately provocative ways, seemingly hoping to kick up a controversy around particular techniques or findings and thereby change others' practices. In some instances methodologists succeed in generating debate and become key figures in these disputes, while in others they create a repository of knowledge that is mobilized by others in times of disagreement. Current conversations about reproducibility in science offer examples of the various ways methodologists might participate in scientific controversies.

In psychology, methodologists have played key roles in generating debate about common practices within the field that might contribute to irreproducibility. Jeremy Freese and David Peterson (2018) point out that the "epistemic activists" who have been the most vocal advocates for change in this debate are themselves social psychologists, members of the subfield of psychology that has attracted the most substantial criticism. These epistemic activists are also, I would argue, methodologists. For example, one of the early calls for attention to reproducibility in psychology came from Brian Nosek, a social psychologist specializing in implicit attitudes (Open Science Collaboration 2012). Nosek had previously conducted replications of his own and others' work as a means of assessing the stability of established findings (Nosek and Hansen 2008; Joy-Gaba and Nosek 2010) and had a longstanding interest in publication practices and the incentive structure of academic research (Nosek 2017). Nosek founded the Open Science Collaboration with Jeffrey Spies, a former PhD student of Nosek's who self-describes as a "methodologist" ("Jeffrey R. Spies, Ph.D." n.d.). Through the Open Science Collaboration, Nosek and Spies used replication as a technique to generate empirical evidence that many findings in psychology were not as robust as commonly believed-the project found that on average the effect sizes in the replication studies were half the magnitude of the effect sizes in the originals (Open Science Collaboration 2015). This finding generated a great deal of controversy within the field about whether psychology was facing a "replication crisis" (Maxwell, Lau, and Howard 2015; Barrett 2015), as well as a series of proposals for reforming incentives and publication practices, some coming from Nosek himself (Nosek et al. 2015). This is an example where methodologists continued to probe what many psychologists considered to be established findings, and in doing so became key figures in a controversy not only about the findings themselves but also about scientific publication practices and the legitimacy of the field as a whole.

Methodologists can also play a less direct role in generating scientific controversies by generating evidence that others can draw on, as in the case of reproducibility conversations in

s In other work I have explored how changing practices around environmental enrichment in animal housing facilities raise exactly this problem (Nelson 2016)_arguments for "improved" housing practices act as an implicit critique of previous scientific and animal welfare practices. 
biomedicine. The National Institute of Neurological Disorders and Stroke (NINDS), one of the first institutes at the National Institutes of Health (NIH) to publicly address issues about reproducibility and rigor, could be thought of as a consumer rather than a producer of methodological knowledge. In a publication by NINDS leadership calling for greater attention to reproducibility, the authors drew on an eclectic collection of evidence from methodologists to make their case (Landis et al. 2012). The paper does not report on any new data collected by the NINDS (eg. on rates of reproducibility in NINDS sponsored research). Instead it relies on existing research that questions taken-for-granted methods: a study reporting that papers published in highly reputable journals often lack important information related to experimental design (Hackam and Redelmeier 2006), another showing that papers that don't report this important information are more likely to report biased results (Macleod et al. 2008), and so on. Even in cases where methodologists are not key players in scientific controversies, their data may still play an important role in the trajectory of the dispute.

\section{Conclusion}

I have put forward a new analytical category of scientific actors in this paper, with two goals in mind. First, I aim to provide an alternative method for STS scholars to recover the contingencies, alternatives, and uncertainties erased through the process of naturalizing scientific objects, particularly in cases where there are few active controversies or where existing records make it difficult to recover the traces of science in action. Just as seeking out controversies allows analysts to benefit from the work done by scientists to articulate uncertainties in scientific work, seeking out methodologists allows analysts to benefit from those who work to keep those uncertainties in view. Second, I have offered some preliminary thoughts on how the work done by methodologists can enhance our understanding of scientific controversies. Although a good deal of attention in STS has been devoted to how controversies come to closure, much less attention has been directed to the conditions under which objects or issues-especially seemingly settled objects or issues-become controversial.

I have focused in this paper on controversies to illustrate the value of the concept, but there are many questions that could be asked about the role that methodologists play in other aspects of science, such as field formation and changes in practice. For example, when do methodologists' interventions succeed in shifting scientific practices, and when are they ignored or rebuffed (Kirk 2012a)? Under what conditions are methodological activities treated as legitimate scientific endeavors, and when are they relegated to other fields such as philosophy (Cowles 2016)? What role do methodologists play in the establishment of new scientific fields, or are the distinctions between epistemic and technical things typically too blurry in a field's early days for the category to hold? What is the relationship of methodologists to the emerging field of meta-science (or meta-research, or research-on-research)? I hope that STS scholars might explore

\footnotetext{
- A notable exception would be STS studies of ignorance and doubt, such as Naomi Oreskes and Erik Conway's (2011) work on how industry actors and conservative think tanks have generated controversy about the stability of scientific findings through the production of competing findings.
} 
these and other questions in order to develop more fine-grained understandings of the different kinds of work performed by scientists, the relationship of this work to scientists' identities and positions in fields, and the role that this work plays in the evolution of fields.

\section{Author Biography}

Nicole C. Nelson is an Assistant Professor of Science and Technology Studies in the department of Medical History and Bioethics at the University of Wisconsin-Madison. She studies complexity and uncertainty in biomedicine, with a particular focus on preclinical research with animal models. Her recent book, Model Behavior, is an ethnographic exploration of what laboratory research looks like when scientists assume the phenomena they are studying are complex. She is also a Collaborating Editor at the journal Social Studies of Science.

\section{Acknowledgements}

This work was supported by a fellowship from the Radcliffe Institute for Advanced Study at Harvard University. My thanks to Sergio Sismondo for a conversation that inspired me to write this paper and to Harald Kliems for his copyediting assistance. I'm also grateful to the Minnesota Center for the Philosophy of Science and the History of Science, Technology, and Medicine program for the excellent feedback they provided on a draft version of this paper presented as part of their colloquium series.

\section{References}

Barrett, Lisa Feldman. 2015. "Psychology Is Not in Crisis." New York Times, September 1, 2015, sec. Opinion.

Casper, Monica J., and Adele E. Clarke. 1998. "Making the Pap Smear into the 'Right Tool' for the Job: Cervical Cancer Screening in the USA, circa 1940-95." Social Studies of Science 28 (2): 255-90. https: / / doi.org/10.1177/ 030631298028002003.

Clarke, Adele E., and Susan Leigh Star. 2008. "The Social Worlds Framework: A Theory/Methods Package." In The Handbook of Science and Technology Studies, edited by Edward Hackett, Olga Amsterdamska, Michael Lynch, and Judy Wajcman, 113-38. Cambridge, MA: MIT Press.

Collins, H. M. 1981. “The Place of the 'Core-Set' in Modern Science: Social Contingency with Methodological Propriety in Science." History of Science 19 (1): 6-19. https: / / doi.org/10.1177/007327538101900102.

Cowan, Ruth Schwartz. 1976. “The 'Industrial Revolution' in the Home: Household Technology and Social Change in the 20th Century." Technology and Culture 17 (1): 1-23. https: / / doi.org/10.2307/3103251.

Cowles, Henry M. 2016. "The Age of Methods: William Whewell, Charles Peirce, and Scientific Kinds." Isis 107 (4): 722-37. https:/ / doi.org/10.1086/689697. 
Crawley, Jacqueline N. 2007. What's Wrong With My Mouse: Behavioral Phenotyping of Transgenic and Knockout Mice. 2nd ed. Hoboken, NJ: Wiley-Liss.

Fraser, Leanne M., Richard E. Brown, Ahmed Hussin, Mara Fontana, Ashley Whittaker, Timothy P. O’Leary, Lauren Lederle, Andrew Holmes, and André Ramos. 2010. "Measuring Anxiety- and Locomotion-Related Behaviours in Mice: A New Way of Using Old Tests." Psychopharmacology 211 (1): 99-112. https:/ / doi.org/10.1007/ s00213-010-1873-0.

Freese, Jeremy, and David Peterson. 2018. "The Emergence of Statistical Objectivity: Changing Ideas of Epistemic Vice and Virtue in Science." Sociological Theory 36 (3): 289-313. https: / / doi.org/10.1177/0735275118794987.

Hackam, Daniel G., and Donald A. Redelmeier. 2006. "Translation of Research Evidence from Animals to Humans." JAMA $296 \quad$ (14): 1727-32. https: / / doi.org/10.1001/jama.296.14.1731.

Hagenbuch, Niels, Joram Feldon, and Benjamin K Yee. 2006. "Use of the Elevated Plus-Maze Test with Opaque or Transparent Walls in the Detection of Mouse Strain Differences and the Anxiolytic Effects of Diazepam." Behavioural Pharmacology 17 (1): 31-41.

Hippel, Eric von. 1986. "Lead Users: A Source of Novel Product Concepts." Management Science 32 (7): 791-805. https:/ / doi.org/10.1287/mnsc.32.7.791.

Hughes, Thomas P. 1979. “The Electrification of America: The System Builders." Technology and Culture 20 (1): 124-61. https:/ / doi.org/10.2307/3103115.

“Jeffrey R. Spies, Ph.D.” n.d. Accessed November 26, 2019. https: / jeffspies.com/.

Jordan, Kathleen, and Michael Lynch. 1992. "The Sociology of a Genetic Engineering Technique: Ritual and Rationality in the Performance of the 'Plasmid Prep.'” In The Right Tools for the Job: At Work in 20th Century Life Sciences, edited by Adele E. Clarke and Joan H. Fujimura. Princeton, NJ: Princeton University Press.

Joy-Gaba, Jennifer A., and Brian A. Nosek. 2010. "The Surprisingly Limited Malleability of Implicit Racial Evaluations." Social Psychology $41 \quad$ (3): 137-46. https: / / doi.org/10.1027/1864-9335/a000020.

Kirk, Robert G. W. 2012a. "'Standardization through Mechanization': Germ-Free Life and the Engineering of the Ideal Laboratory Animal." Technology and Culture 53 (1): 61-93. https: / / doi.org/10.1353/tech.2012.0025.

—_ 2012b. "'Life in a Germ-Free World': Isolating Life from the Laboratory Animal to the Bubble Boy." Bulletin of the History of Medicine 86 (2): 237-75 . https://doi.org $10.1353 /$ bhm.2012.0028

Knorr-Cetina, Karin D. 1999. Epistemic Cultures: How the Sciences Make Knowledge. Cambridge, MA: Harvard University Press.

Kurt, M, A C Arik, and S Celik. 2000. "The Effects of Sertraline and Fluoxetine on Anxiety in the Elevated Plus-Maze Test in Mice." Journal of Basic and Clinical Physiology and Pharmacology 11 (2): 173-80. https: / / doi.org/10.1515/JBCPP.2000.11.2.173.

Landis, Story C., Susan G. Amara, Khusru Asadullah, Chris P. Austin, Robi Blumenstein, Eileen W. Bradley, Ronald G. Crystal, et al. 2012. "A Call for Transparent Reporting to Optimize 
the Predictive Value of Preclinical Research." Nature 490 (7419): 187-91. https: / / doi.org/10.1038/nature11556.

Latour, Bruno. 1987. Science in Action: How to Follow Scientists and Engineers through Society. Cambridge, MA: Harvard University Press.

— 2 2005. Reassembling the Social: An Introduction to Actor-Network-Theory. Oxford, UK: Oxford University Press, USA.

Lewis, Jamie, and Andrew Bartlett. 2013. "Inscribing a Discipline: Tensions in the Field of Bioinformatics." New Genetics and Society 32 (3): 243-63. https: / / doi.org/10.1080/14636778.2013.773172.

Macleod, Malcolm, Bart H. van der Worp, Emily S. Sena, David W. Howells, Ulrich Dirnagl, and Geoffrey A. Donnan. 2008. "Evidence for the Efficacy of NXY-059 in Experimental Focal Cerebral Ischaemia Is Confounded by Study Quality." Stroke 39 (10): 2824-29. https: / / doi.org/10.1161/STROKEAHA.108.515957.

Maxwell, Scott E., Michael Y. Lau, and George S. Howard. 2015. "Is Psychology Suffering from a Replication Crisis? What Does 'Failure to Replicate' Really Mean?" American Psychologist 70 (6): 487-98. https: / / doi.org/10.1037 / a0039400.

Milner, L. C., and J. C. Crabbe. 2008. "Three Murine Anxiety Models: Results from Multiple Inbred Strain Comparisons." Genes, Brain, and Behavior 7 (4): 496-505. https: / / doi.org/10.1111/j.1601-183X.2007.00385.x.

Moser, P. C. 1989. "An Evaluation of the Elevated Plus-Maze Test Using the Novel Anxiolytic Buspirone." Psychopharmacology 99 (1): 48-53. https: / / doi.org/10.1007 / BF00634451.

Mukerji, Chandra. 2007. "Controversy Studies." In The Blackwell Encyclopedia of Sociology, edited by George Rizter. Hoboken, NJ: Blackwell Publishing. https: / / doi.org/10.1002/9781405165518.wbeosc130.

Nelson, Nicole C. 2013. "Modeling Mouse, Human, and Discipline: Epistemic Scaffolds in Animal Behavior Genetics." Social Studies of Science 43 (1): 3-29. https: / / doi.org/10.1177/0306312712463815.

—_ 2016. "Model Homes for Model Organisms: Intersections of Animal Welfare and Behavioral Neuroscience around the Environment of the Laboratory Mouse." BioSocieties 11 (1): 46-66. https: / / doi.org/10.1057/ biosoc.2015.19.

—_. 2018. Model Behavior: Animal Experiments, Complexity, and the Genetics of Psychiatric Disorders. Chicago, IL: University of Chicago Press.

Nosek, B. A., G. Alter, G. C. Banks, D. Borsboom, S. D. Bowman, S. J. Breckler, S. Buck, et al. 2015. "Promoting an Open Research Culture." Science 348 (6242): 1422-25. https: / / doi.org/10.1126/ science.aab2374.

Nosek, Brian. 2017. "Why Are We Working so Hard to Open up Science? A Personal Story." Center for Open Science (blog). December 8, 2017. https://cos.io/blog/why-are-weworking-so-hard-open-science-personal-story/.

Nosek, Brian A., and Jeffrey J. Hansen. 2008. "The Associations in Our Heads Belong to Us: Searching for Attitudes and Knowledge in Implicit Evaluation." Cognition \& Emotion 22 (4): 553-94. https:/ / doi.org/10.1080/02699930701438186. 
Open Science Collaboration. 2012. “An Open, Large-Scale, Collaborative Effort to Estimate the Reproducibility of Psychological Science." Perspectives on Psychological Science 7 (6): 65760. https: / / doi.org/10.1177/1745691612462588.

—_ 2015. "Estimating the Reproducibility of Psychological Science." Science 349 (6251): aac4716. https: / / doi.org/10.1126/ science.aac4716.

Oreskes, Naomi, and Erik M. Conway. 2011. Merchants of Doubt: How a Handful of Scientists Obscured the Truth on Issues from Tobacco Smoke to Global Warming. New York: Bloomsbury Press.

Oudshoorn, Nelly, and Trevor Pinch. 2003. “Introduction: How Users and Non-Users Matter." In How Users Matter: The Co-Construction of Users and Technology, edited by Nelly Oudshoorn and Trevor Pinch, 1-25. Cambridge, MA: MIT Press.

Panofsky, Aaron L. 2011. "Field Analysis and Interdisciplinary Science: Scientific Capital Exchange in Behavior Genetics." Minerva 49 (3): 295. https:// doi.org/10.1007/s11024011-9175-1.

Rasmussen, Nicolas. 2014. Gene Jockeys: Life Science and the Rise of Biotech Enterprise. Baltimore, MD: Johns Hopkins University Press.

Rheinberger, Hans-Jorg. 1997. Toward a History of Epistemic Things: Synthesizing Proteins in the Test Tube. Stanford, CA: Stanford University Press.

Silva, M. T., C. R. Alves, and E. M. Santarem. 1999. "Anxiogenic-like Effect of Acute and Chronic Fluoxetine on Rats Tested on the Elevated plus-Maze." Brazilian Journal of Medical and Biological Research 32 (3): 333-39.

Star, Susan Leigh. 2010. "This is Not a Boundary Object: Reflections on the Origins of a Concept." Science, Technology, \& Human Values 35 (5): 601-17.

https:// doi.org/10.1177/0162243910377624.

Wylie, Caitlin Donahue. 2015. “The Artist's Piece Is Already in the Stone': Constructing Creativity in Paleontology Laboratories." Social Studies of Science 45 (1): 31-55. https: / / doi.org/10.1177/0306312714549794. 